\title{
Potent optogenetic inhibition of behavior with anion channelrhodopsins
}

\author{
Farhan Mohammad1, James C. Stewart ${ }^{2}$, Stanislav Ott', Katarina Chlebikova1, Jia Yi \\ Chua', Tong-Wey Koh${ }^{4}$, Joses $\mathrm{Ho}^{2}$, Adam Claridge-Chang1, 2, 3, 5 \\ 1. Program in Neuroscience and Behavioral Disorders, Duke-NUS Medical School, Singapore 138673 \\ 2. Institute for Molecular and Cell Biology, Agency for Science Technology and Research, Singapore 138673 \\ 3. Department of Physiology, National University of Singapore, Singapore 138673 \\ 4. Temasek Life Sciences Laboratory, 1 Research Link, Singapore 117604 \\ 5. Correspondence: claridge-chang.adam@duke-nus.edu.sg
}

\begin{abstract}
Optogenetics employs light exposure to manipulate physiology in genetically modified organisms. There are abundant tools for optogenetic excitation of neuronal activity, but the limitations of current activity photo-inhibitors present an obstacle to demonstrating the necessity of specific neuronal circuits. Here we show that anion channelrhodopsins can be used to specifically and rapidly inhibit a range of systems involved in Drosophila locomotion, wing expansion, memory retrieval and gustation, demonstrating their broad utility to the circuit analysis of behavior.
\end{abstract}

\section{Introduction}

Our ability to understand the neuronal control of behavior has been transformed by the advent of techniques enabling researchers to precisely manipulate neuronal activity in transgenic animals (Sweeney et al. 1995; Johns et al. 1999; Kitamoto 2001; Zemelman et al. 2002; Boyden et al. 2005; Roth 2016; Hamada et al. 2008; Tye and Deisseroth 2012). Optogenetics is one such technique which uses controlled light exposure to reversibly modulate the activity of light-sensitive ion channels. Optogenetic actuators can be expressed in genetically-modified organisms with circuit specificity (Zemelman et al. 2002) in behaving animals (Lima and Miesenböck 2005) with millisecond-resolution (Boyden et al. 2005). However, while optogenetic activators are in widespread use, the toolkit of optogenetic inhibitors of neuronal activity is more limited: consequently, in a number of experimental systems it is relatively much easier to show that a specific neural circuit is sufficient for any given function, yet demonstrating the necessity for that circuit remains problematic. Suppression of neuronal excitability uses either an influx of anions or an efflux of cations; this has previously been achieved using lightdriven chloride (Zhang et al. 2007) or proton pumps (Chow et al. 2010), but they require high-density expression and intense light for effective inhibition, limiting their utility. Recently, a new class of inhibitory, anion-conducting, light-gated channels has been developed, including channelrhodopsins engineered to conduct chloride ions (Wietek et al. 2014; Berndt et al. 2014), and two naturallyevolved anion channelrhodopsins cloned from an alga (Govorunova et al. 2015). The algal Guillardia theta anion channelrhodopsins 
A
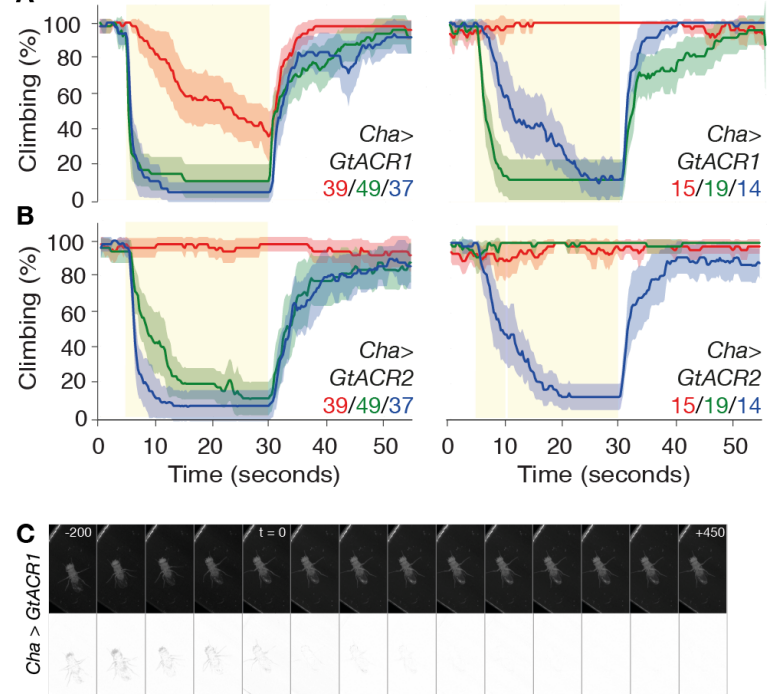

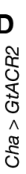
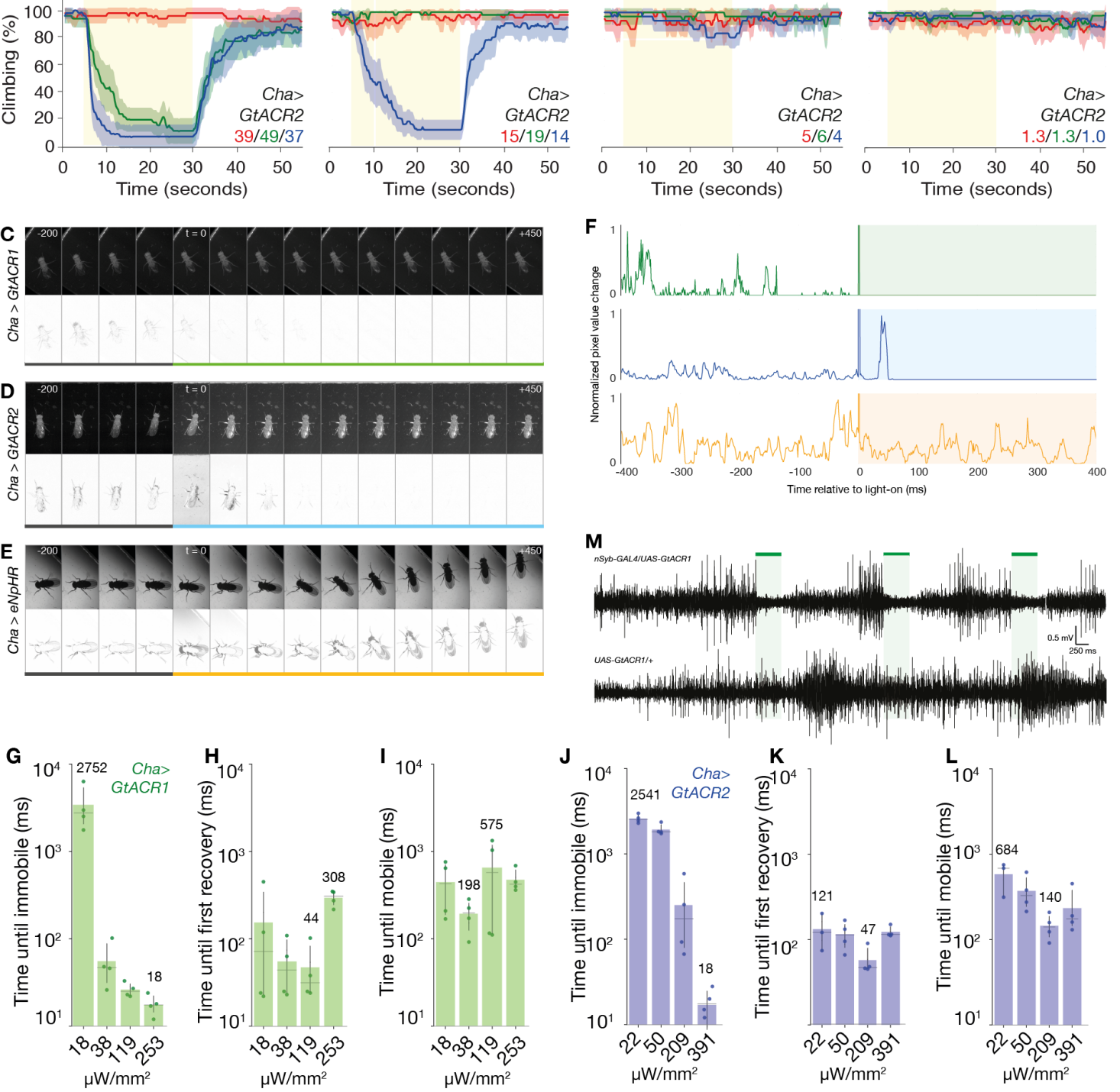

Figure 1. Guillardia theta anion channelrhodopsins are potent inhibitors of motor function and neuronal spiking.

A. Flies expressing GtACR1 in cholinergic neurons (Cha-Gal4>UAS-GtACR1) fell from a vertical surface when illuminated. Light intensities in $\mu \mathrm{W} / \mathrm{mm}^{2}$ are given in each panel. The proportion of climbing flies is given as a percentage of flies outside the floor area of the chamber. At the highest setting, flies fell in response to green, blue and red light, but responded only to green light at lower intensities. Each solid trace is the mean of 3 experiments ( 48 flies), line color corresponds to the color of illumination from a projector, error ribbons are $95 \%$ confidence intervals.

B. Flies expressing GtACR2 (Cha>GtACR2) fell in response to blue and green light at the highest intensity; green light had little effect at $19 \mu \mathrm{W} / \mathrm{mm}^{2}$, blue light $\left(14 \mu \mathrm{W} / \mathrm{mm}^{2}\right)$ was sufficient to causing falling.

C. Representative Muybridge series from a high-speed video (1000 frames per second) during light onset (top row) show that green light illumination (peak $525 \mathrm{~nm}, 38 \mu \mathrm{W} / \mathrm{mm}^{2}$ ) of a fly expressing GtACR1 in cholinergic neurons elicited a rapid onset of immobility. Frames are spaced at $50 \mathrm{~ms}$ intervals, numbers indicate time relative to illumination start in $\mathrm{ms}$. Difference images between consecutive frames (bottom row) map the motion. Coloured bar indicates frames where the fly is illuminated. 
Figure 1. continued.

D. Muybridge series indicates that illumination with $253 \mu \mathrm{W} / \mathrm{mm}^{2}$ of blue light rapidly paralyzed the Cha-Gal4>UAS-GtACR2 subject fly. Upper row shows video frames, lower row shows difference images.

E. A representative series shows that illumination with amber light (peak $591 \mathrm{~nm}, 495 \mu \mathrm{W} / \mathrm{mm}^{2}$ ) failed to interrupt the movement of a Cha-Gal4>UAS-eNpHR fly.

F. Difference images from the videos in panels C-E were used to quantify motion. Plots show the normalized sum of pixel value differences across a region of interest that contained the moving fly. Cha-Gal4> GtACR flies were motionless within $100 \mathrm{~ms}$, while illuminated Cha-Gal4>eNpHR flies showed similar pixel changes before and during light exposure. The pixel difference spike observed at light onset is due to imperfect exclusion of visible light by the longpass filter.

G. Four Cha-Gal4>UAS-GtACR1 flies were recorded at $1000 \mathrm{fps}$ and frame-by-frame inspection was used to quantify the time until each fly was immobilized after lights-on. The horizontal axis indicates the four light intensities tested, the numerals in the panel indicate the medians of the fastest and slowest responses. The time until immobile shortened dramatically with increasing green light intensity (peak $525 \mathrm{~nm}$ ). Error bars are $95 \%$ confidence intervals.

H-I. Times between cessation of illumination and the first sign of recovery, and times to full mobility, over four light intensities. There was no strong relationship between light intensity and recovery times.

J-L. Times of immobility onset and recovery of four Cha-Gal4>UAS-GtACR2 flies over a range of intensities.

M. Representative recordings from larval segmental nerves. Pulses of green light (500 ms, 24 $\mu \mathrm{W} / \mathrm{mm}^{2}$, green lines and shading) inhibited action potentials in nerves expressing GtACR1 (nSyb>GtACR1, pan-neuronal expression), but not in control larvae (UAS-GtACR1/+).

(GtACRs) possess several attractive features as optogenetic inhibitors: they have much higher conductances than other inhibitory optogenetic tools, are rapidly responsive, require only low light intensities for activation, and are comprised of both a cyan-gated (GtACR1, maximal sensitivity at $515 \mathrm{~nm}$ ) and a blue-gated channel (GtACR2, maximal sensitivity at $470 \mathrm{~nm}$ ) (Govorunova et al. 2015). Considering these properties, we hypothesized that the GtACRs could be employed to effectively optogenetically inhibit neuronal circuits in a model organism. Here we show that both GtACR1 and GtACR2 potently, rapidly, and reversibly inhibit a range of behaviors in Drosophila during controlled exposure to consumer light sources.

\section{Results}

\section{Climbing flies fall when GtACRs are light-activated in choliner- gic neurons}

Genes coding for the GtACRs were expressed in cells that release the neurotransmitter acetylcholine (Kitamoto 2001; Salvaterra and Kitamoto 2001). While climbing on a vertical surface, Drosophila expressing the cyan-gated GtACR1 fell when exposed to just 1.3 $\mu \mathrm{W} / \mathrm{mm}^{2}$ green light from a projector (Figure 1A, Video 1). GtACR1 flies (Cha>GtACR1) were also susceptible to blue and red light (at $\geq 14 \mu \mathrm{W} / \mathrm{mm}^{2}$ and $39 \mu \mathrm{W} / \mathrm{mm}^{2}$ respectively). Flies expressing the blue-gated GtACR2 in cholinergic neurons fell in response to blue light only at $14 \mu \mathrm{W} / \mathrm{mm}^{2}$ (Figure $1 \mathrm{~B}$ ) and to both blue and green light at the highest intensities (but not red light). By contrast, flies expressing enhanced Natronomonas pharaonis halorhodopsin (eN$\mathrm{pHR}$ ) did not fall when illuminated with $39 \mu \mathrm{W} / \mathrm{mm}^{2}$ red projector light. Control flies were unaffected by light (Figure 2A). 

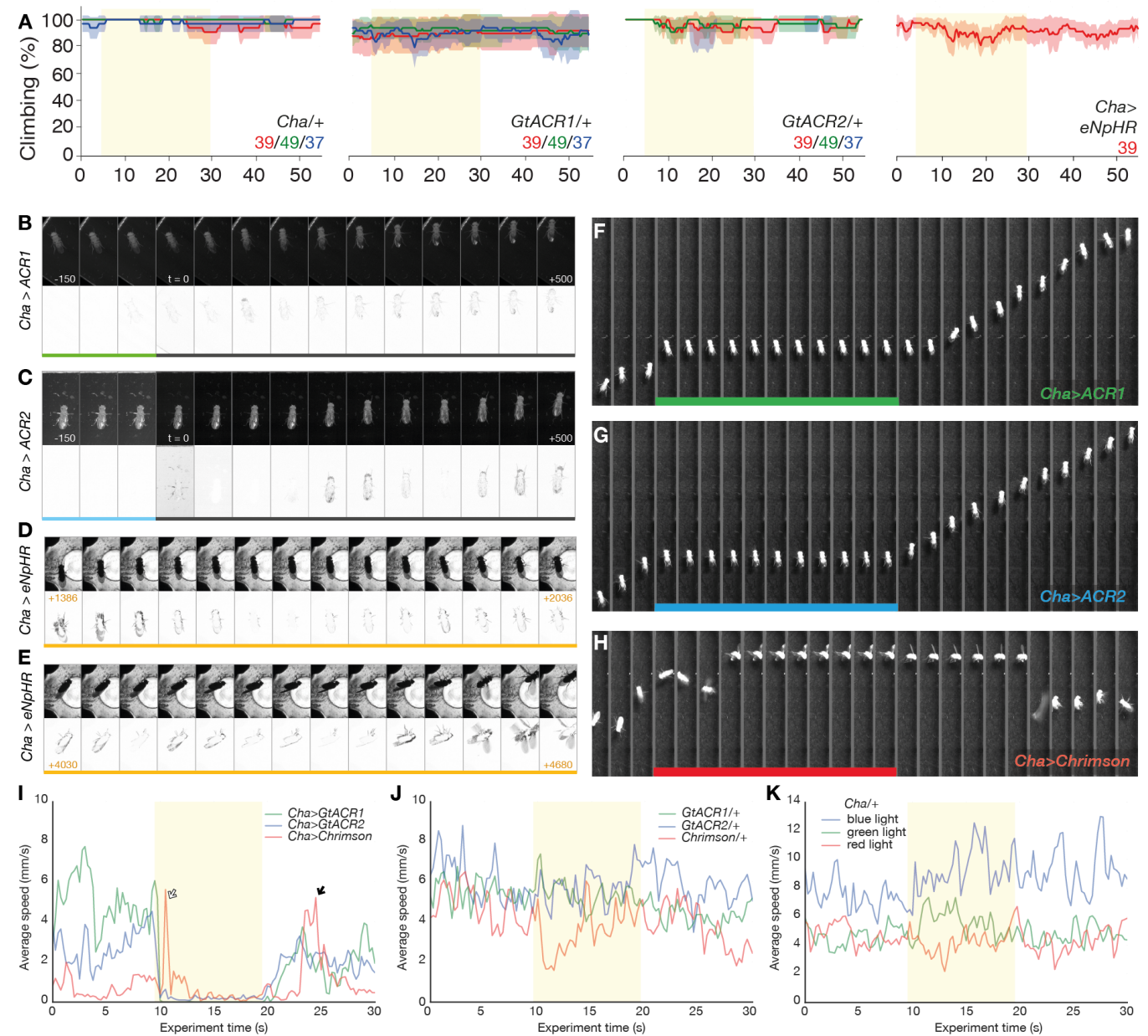

Figure 2. Anion channelrhodopsin action in the Drosophila cholinergic system.

A. Control flies carrying either the driver or GtACR transgenes alone did not fall when illuminated with different wavelengths and intensities of light. The indicated colored light intensities are shown in $\mu \mathrm{W} / \mathrm{mm}^{2}$. Similarly, the climbing performance of Drosophila expressing eNpHR in cholinergic cells remained largely unimpaired when the flies were illuminated with $39 \mu \mathrm{W} / \mathrm{mm}^{2}$ of red light.

B. Muybridge series illustrates the recovery of a Cha-Gal4>UAS-GtACR1 fly after light-off. Motion in the difference series prior to lights-off indicates that the fly was immobile, though not motionless. Inter-frame steps are $50 \mathrm{~ms}$.

C. Recovery of a Cha-Gal4>UAS-GtACR2 fly over a 500 ms interval after light-off.

D-E. A fly with a Cha-Gal4>UAS-eNpHR genotype exposed to $1900 \mu \mathrm{W} / \mathrm{mm}^{2}$ (i.e. sitting $3 \mathrm{~mm}$ above the LED) was only sporadically immobilized.

F. A Cha>GtACR1 fly entered into a static paralysis upon illumination with green projector light (92 $\mu \mathrm{W} / \mathrm{mm}^{2}$ ). Frames are separated by $1 \mathrm{~s}$ intervals.

G. A Cha>GtACR2 fly underwent static immobilization during exposure to blue light $\left(67 \mu \mathrm{W} / \mathrm{mm}^{2}\right)$, though retained some leg movement.

H. A Cha>CsChrimson fly underwent an active convulsion for several seconds upon illumination with red light $\left(70 \mu \mathrm{W} / \mathrm{mm}^{2}\right)$. During paralysis, the wings were extended; after light-off, seizure continued for $\sim 6$ seconds and was followed by another active convulsion before the fly regained a standing pose (last frame).

I. Average speed of the three strains illustrated in $\mathrm{F}-\mathrm{H}$, before during and after exposure to projector light (Cha>GtACR1, green $92 \mu \mathrm{W} / \mathrm{mm}^{2}$; Cha>GtACR2, blue $67 \mu \mathrm{W} / \mathrm{mm}^{2}$; Cha>CsChrimson, red 70 $\mu \mathrm{W} / \mathrm{mm}^{2}$ ). Lines are the mean speed of seven flies of each genotype. The GtACR flies are rapidly immobilized; the CsChrimson flies had increased speed after light-on that is related to convulsions (white arrow). The Cha>CsChrimson flies also convulse during recovery (black arrow).

J. The walking speed of responder control flies is largely unchanged by light exposure, $N=15,15$, 15.

K. The driver control (Cha-Gal4/+) line is unresponsive to projector illumination of any color, $\mathrm{N}=$ $15,15,15$. 
GtACR activation in cholinergic neurons induces rapid, complete and reversible paralysis

Some of the fallen Drosophila moved during GtACR activation (Video 1), revealing incomplete inhibition of $\mathrm{Cha}^{+}$neurons. Examining the motion of individual flies with a high frame-rate camera revealed that illumination with green light using light-emitting diodes (LEDs) induced complete and rapid immobility in Cha>GtACR1 flies with intensities $38 \mu \mathrm{W} / \mathrm{mm}^{2}$ and above (Figure 1C). At higher powers, immobilization was observed in a fraction of all-trans-retinal-fed UAS-GtACR1/+ flies $\left(36 \%\right.$ [95CI 12, 68] at $253 \mu \mathrm{W} / \mathrm{mm}^{2}, \mathrm{~N}$ $=11 ; 13 \%[95 \mathrm{CI} 2,31]$ at $119 \mu \mathrm{W} / \mathrm{mm}^{2}, \mathrm{~N}=15$; zero at the lower intensities, $\mathrm{N}=12,9$ ), possibly due to 'leaky' expression in the absence of a driver transgene. In Cha>GtACR2 flies, $391 \mu \mathrm{W} / \mathrm{mm}^{2}$ blue light induced motionless paralysis for the entire duration of light exposure (Figure 1D); an identical light level had no visible effect on control $U A S-G t A C R 2 /+$ flies. Illumination of Cha>eNpHR flies with $495 \mu \mathrm{W} / \mathrm{mm}^{2}$ amber light failed to have any visible effect (Figure 1E); Cha>eNpHR animals were also placed $3 \mathrm{~mm}$ above an LED emitter $\left(\sim 1900 \mu \mathrm{W} / \mathrm{mm}^{2}\right)$ which resulted in sporadic paralysis, confirming that these flies carried active eNpHR (Figure 2D-E, Video 2E). Video analysis indicated that Cha>GtACR1 and Cha $>$ GtACR 2 paralysis onset times were strongly dependent on light intensity, with millisecond-scale onsets occurring at powers 38 $\mu \mathrm{W} / \mathrm{mm}^{2}$ and $391 \mu \mathrm{W} / \mathrm{mm}^{2}$ and above, respectively (Figure $1 \mathrm{G}, \mathrm{J}$ ). Recovery times were not dependent on light intensity (Figure $1 \mathrm{H}-\mathrm{I}$, $\mathrm{K}-\mathrm{L}$, Figure 2B-C).

\section{Profound differences between GtACR-induced cholinergic paralysis and CsChrimson-induced seizure}

The GtACRs are potent inhibitors of action potential firing in several cell types (Govorunova et al. 2015; Mahn et al. 2016), however chloride conductances can have various effects on membrane potential (hyperpolarization, depolarization, shunting) depending on a cell's chloride reversal potential (Knoflach, Hernandez, and Bertrand 2016). GtACR1 photocurrents have been observed to induce transient synaptic release at light-on, an effect attributed to chloride-mediated depolarization at the axon terminus (Mahn et al. 2016; Wiegert and Oertner 2016). We hypothesized that the GtACRs were inducing paralysis by neuronal activation rather than silencing and that an activating photochannel would thus phenocopy the GtACR-mediated paralysis. Activation of the cholinergic system with CsChrimson refuted this hypothesis, revealing that while illuminated Cha>CsChrimson flies underwent convulsions after lighton, followed by a tetanic pose, Cha>GtACR flies rapidly entered a static paralysis and retained their pre-light pose (Figure 1C-E, Figure $2 \mathrm{~F}-\mathrm{K}$, Video 3 ). These profoundly different effects are consistent with the idea that GtACRs act to inhibit action potentials (Govorunova et al. 2015; Mahn et al. 2016). 
bioRxiv preprint doi: https://doi.org/10.1101/082255; this version posted October 20, 2016. The copyright holder for this preprint (which was not certified by peer review) is the author/funder, who has granted bioRxiv a license to display the preprint in perpetuity. It is made available under aCC-BY-NC 4.0 International license.
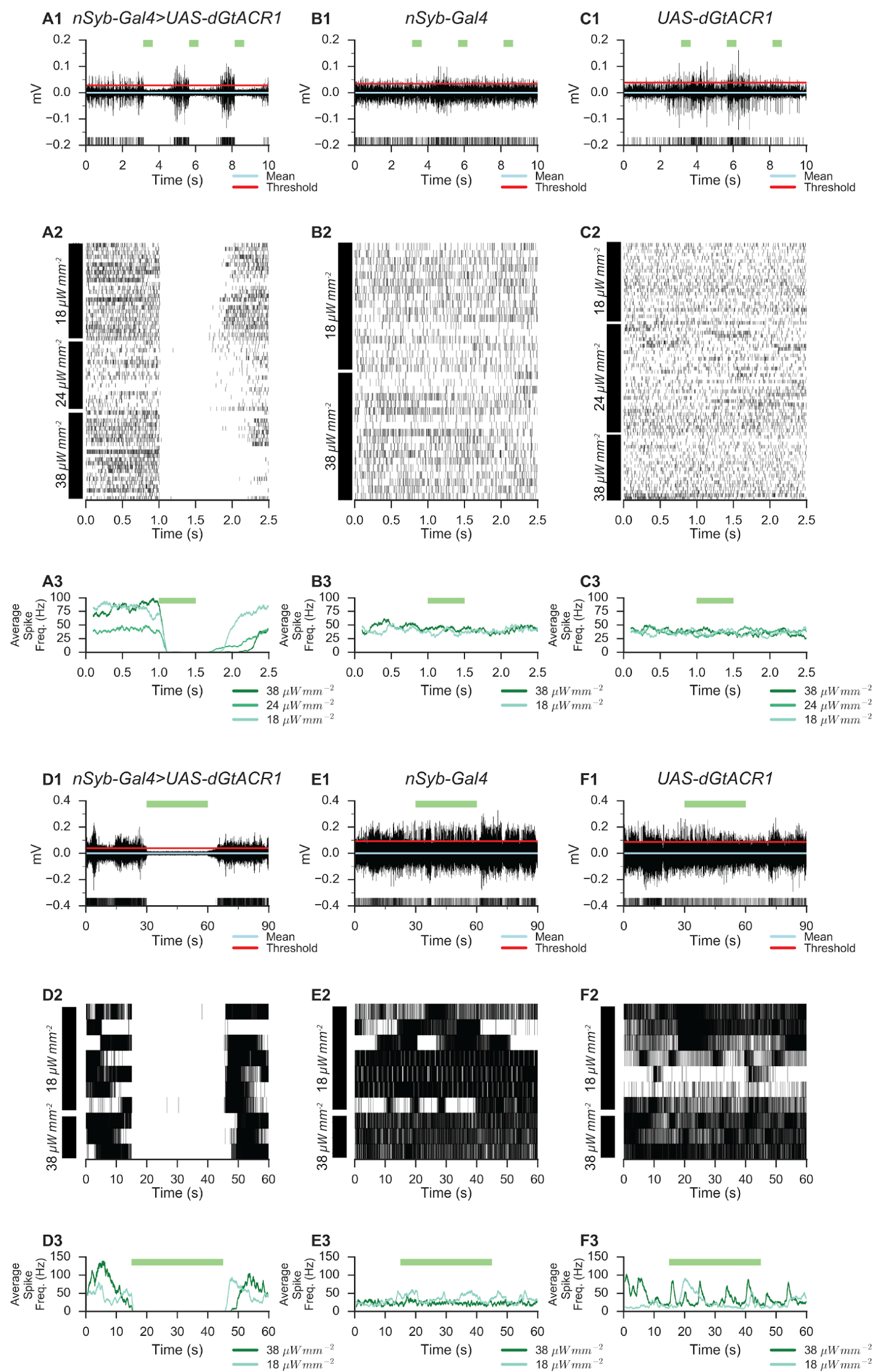
Figure 3. Illuminated GtACR silences a Drosophila larval nerve.

A. A representative trace (A1) from an extracellular recording from a larval abdominal 3 nerve showing the inhibitory effect of three $500 \mathrm{~ms}$ pulses of green light $\left(38 \mu \mathrm{W} / \mathrm{mm}^{2}\right)$ in a $n S y b>G t A C R 1$ larva. The red line indicates the voltage threshold used to detect spikes. Rasters of spike timings (A2) from several light intensities $\left(38 \mu \mathrm{W} / \mathrm{mm}^{2}, 24 \mu \mathrm{W} / \mathrm{mm}^{2}\right.$, and $\left.18 \mu \mathrm{W} / \mathrm{mm}^{2}\right)$ and a spike frequency plot (A3) indicate that the time of full activity recovery is longer with more intense light $\left(N_{\text {pulses }}=93, N_{\text {flies }}=3\right) .500 \mathrm{~ms}$ pulses of $38 \mu \mathrm{W} / \mathrm{mm}^{2}$ green light nerves from $n S y b>G$ tACR1 larvae suppressed spiking frequency by $\Delta=-98.5 \%[95 \mathrm{Cl}-99.2,-97.6], P=3.05 \times 10-$ $39, \mathrm{~N}_{\text {pulses }}=23, \mathrm{~N}_{\text {flies }}=3$. With $500 \mathrm{~ms}$ pulses of $24 \mu \mathrm{W} / \mathrm{mm} 2$ green light, the spiking frequency exhibited a decrease of $-99.0 \%[95 \mathrm{Cl}-99.7,-97.7], P=3.415 \times 10^{-35}, \mathrm{~N}_{\text {pulses }}=21, \mathrm{~N}_{\text {flies }}=3$.

B. Illumination of $n S y b-G a l 4 /+$ control flies with green light $\left(38\right.$ and $\left.18 \mu \mathrm{W} / \mathrm{mm}^{2}\right)$ for $500 \mathrm{~ms}$ had no detectable effect on the rate of identifiable spikes ( $\mathrm{N}_{\text {pulses }}=63, \mathrm{~N}_{\text {flies }}=3$ ).

C. Illumination of UAS-GtACR1/+ control flies for $500 \mathrm{~ms}$ with green light $\left(38,24\right.$, and $\left.18 \mu \mathrm{W} / \mathrm{mm}^{2}\right)$ had no effect on nerve firing ( $\mathrm{N}_{\text {pulses }}=106, \mathrm{~N}_{\text {flies }}=3$ ).

D. Representative recording (D1), raster plot (D2) and frequency plot of nSyb>GtACR1 nerves indicate that firing is almost completely suppressed during an $30 \mathrm{~s}$ illumination epoch. Firing recovers in $<5 \mathrm{~s}$ at $18 \mu \mathrm{W} / \mathrm{mm}^{2}$ and $\sim 10 \mathrm{~s}$ at $38 \mu \mathrm{W} / \mathrm{mm}^{2}$ ( $\mathrm{N}_{\text {pulses }}=10, \mathrm{~N}_{\text {flies }}=3$ ). $30 \mathrm{~s}$ pulses of $38 \mu \mathrm{W} /$ $\mathrm{mm}^{2}$ light completely silenced spikes, $\Delta=-100 \%[95 \mathrm{Cl}-100,-100], \mathrm{P}=0, \mathrm{~N}_{\text {pulses }}=10, \mathrm{~N}_{\text {flies }}=3$.

E. Illumination of $n S y b-G a l 4 /+$ controls for $30 \mathrm{~s}$ had no effect on spiking $\left(\mathrm{N}_{\text {pulses }}=10, \mathrm{~N}_{\text {flies }}=3\right)$.

F. Illumination of UAS-GtACR1/+ controls for $30 \mathrm{~s}$ had no effect on firing $\left(\mathrm{N}_{\text {pulses }}=10, \mathrm{~N}_{\text {flies }}=3\right)$.

\section{GtACR1 illumination silences action potentials in a nerve}

Photo-actuation of GtACR1 expressed in larval abdominal nerves (nSyb>GtACR1, pan-neuronal expression) produced dramatic reductions in spiking frequency, as seen in representative recordings from larval segmental nerves (Figure 1M, Figure 3). For example, $500 \mathrm{~ms}$ pulses of $18 \mu \mathrm{W} / \mathrm{mm}^{2}$ green light suppressed the spiking frequency of $n S y b>G t A C R 1$ larval nerves by $\Delta=-97.8 \%$ relative to the preceding activity [95CI $-96.0,-98.7], P=3.62 \times 10^{-33}, \mathrm{~N}_{\text {pulses }}=22, \mathrm{~N}_{\text {flies }}=$ 3 (Figure 3A). At the same intensity, $30 \mathrm{~s}$ pulses decreased the spiking frequency by $-99.8 \%$ [95CI $-99.4,-100], P=3.83 \times 10^{-16}, \mathrm{~N}_{\text {pulses }}$ $=7, \mathrm{~N}_{\text {flies }}=3$. Across several light intensities and pulse durations tested, we did not observe any decrease in the spiking frequency of control larvae during green light illumination $(n S y b-G a l 4 /+$ and $U A S-G t A C R 1 /+)$. For instance, $500 \mathrm{~ms}$ pulses of $38 \mu \mathrm{W} / \mathrm{mm}^{2}$ green light did not alter the spiking frequency of UAS-GtACR1/+ larval nerves $(\Delta=-0.24 \%$ [95CI $-11.6,+15.5], P=0.97, \mathrm{~N}_{\text {pulses }}=25, \mathrm{~N}_{\text {flies }}=$ 3 , Figure $3 \mathrm{C}$ ). These results verify that GtACRs are potent inhibitors of neuronal excitability in Drosophila.

\section{Illuminating GtACRs in bursicon cells prevents wing expansion}

Bursicon is a neurohormone required for developmental functions including wing expansion after eclosion; inhibition of bursicon release with expression of an inhibitory channel is frequently lethal, and in surviving flies prevents normal wing expansion (Peabody et al. 2008). Flies expressing GtACRs under the control of a Bursicon promoter (Burs-Gal4) were illuminated from 1-2 days after puparium formation (APF) until 9-10 APF before wing expansion was scored. The majority of illuminated Burs $>$ GtACR flies died during development (129 out of 249), while the survivors failed to expand their wings (Figure 4A-B). Expression of an inward rectifying potas- 
A

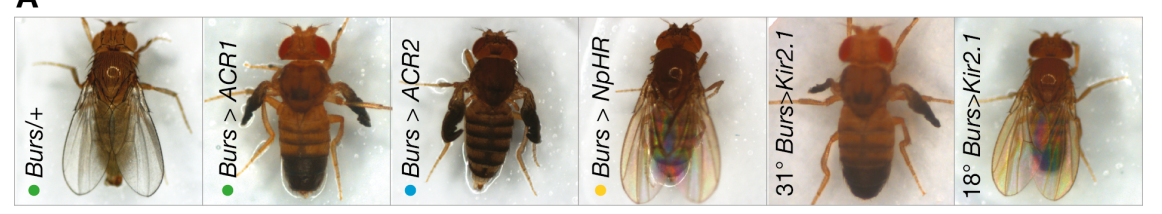

B

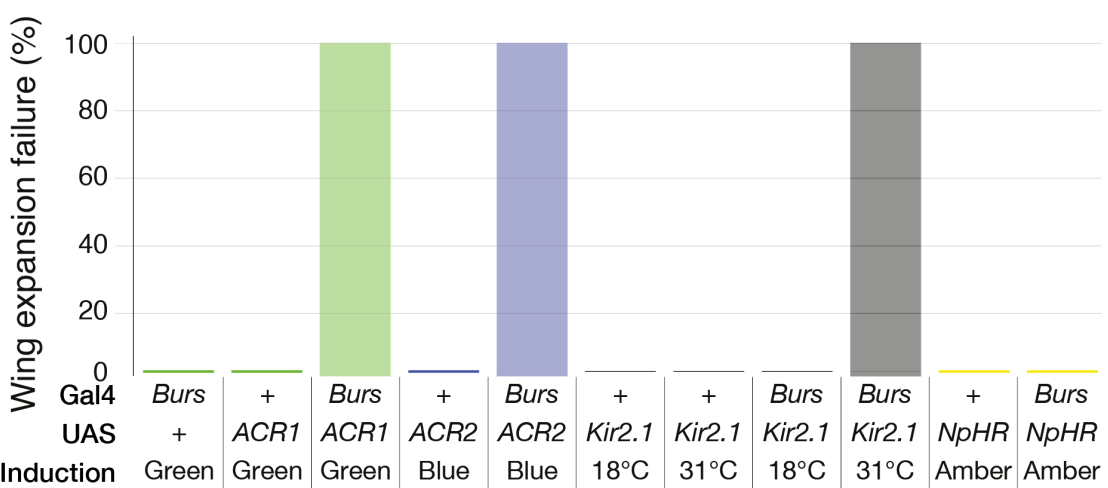

Figure 4. Illuminated anion channelrhodopsin expressed in Bursicon cells inhibit wing expansion.

A. Illumination of flies expressing GtACRs in bursicon-releasing cells (Burs-Gal4; UAS-GtACR1/2) inhibited wing expansion. Flies expressing GtACR1 or GtACR2 in bursicon-releasing cells failed to expand their wings following exposure to green light at $46 \mu \mathrm{W} / \mathrm{mm}^{2}$ or blue light at $106 \mu \mathrm{W} / \mathrm{mm}^{2}$, respectively. Flies with induced Kir2.1 expression in Burs-Gal4 cells also failed to expand their wings. Control flies were unaffected by illumination, as were and Burs>eNpHR flies (amber light at $106 \mu \mathrm{W} / \mathrm{mm}^{2}$ ).

B. Illumination of flies expressing GtACRs in bursicon-releasing cells (Burs-Gal4; UAS-GtACR1/2) inhibited wing expansion. All flies expressing GtACR1 or GtACR2 in bursicon-releasing cells failed to expand their wings following exposure to light, controls were unaffected by light (green at 46 $\mu \mathrm{W} / \mathrm{mm}^{2}$, blue at $106 \mu \mathrm{W} / \mathrm{mm}^{2}$ for GtACR1 and GtACR2 respectively). Induction of Kir2.1 at $31^{\circ} \mathrm{C}$ in Burs-Gal4>UAS-Kir2.1, Tub-Gal $80^{\text {ts }}$ flies produced a $100 \%$ failure in wing expansion. Illumination of Burs-Gal4>UAS-eNpHR flies with $106 \mu \mathrm{W} / \mathrm{mm}^{2}$ amber light had no effect on wing expansion.

Burs/+ (145), Burs-Gal4; UAS-GtACR1 ( $N=114)$, Burs-Gal4; UAS-GtACR1 ( $N=135)$.

sium channel (Kir2.1) (Baines et al. 2001) resulted in total wing expansion failure as previously reported (Peabody et al. 2008), but amber-illuminated Burs $>e N p H r$ flies displayed normal wings.

Actuating GtACR1 in gustatory neurons inhibits the proboscis extension reflex

Drosophila extend their proboscis to sweet liquids, a response known as the proboscis extension reflex (PER) which is dependant upon the activity of neurons expressing Gustatory receptor 64f (Gr64f) (Thoma et al. 2016). Optogenetic activation with CsChrimson is sufficient to elicit PER in the absence of sugar (Klapoetke et al. 2014). When illuminated with green light, flies expressing $U A S$ GtACR1 in Gr64f-Gal4 neurons failed to exhibit PER when presented with a sucrose solution (Figure 5G-H). Exposure of the same flies to red light had essentially no effect on PER (Figure 5A-B). Flies expressing eNpHr in Gr64f showed a reduced PER relative to controls in amber light, $\triangle \mathrm{PER}=-0.26$ [95CI $-0.12,-0.42]$. (Figure 5AB). Expression of Kir2.1 in Gr64f cells reduced PER dramatically, $\triangle \mathrm{PER}=-0.96$ [95CI 0.92, -1.0] (Figure 5A-B). The potent suppres- 
sion of PER by illuminated GtACR1 - the opposite effect to that of CsChrimson-verifies that the anion channelrhodopsin effectively inhibits activity in Gr64f cells.

\section{Flies avoid GtACR1 inhibition of sweet taste receptor neurons}

CsChrimson activation of bitter-sensing Gustatory receptor 66a (Gr66a) neurons was aversive to flies (Figure 5G) (Aso et al. 2014). However, Gr66a>GtACR1 flies were indifferent to green light over a range of intensities known to have effects in other behaviors (Figure $5 \mathrm{H})$, suggesting that the bitter-sensing system is quiet in the absence of a stimulus. Sated flies bearing CsChrimson in their Gr64f sweet taste cells were mildly attracted to dim red light and minimally averted by stronger red light (Figure 5I). In the hungry state, Gr64f $>$ CsChrimson flies had a similar response profile, though avoided the higher intensities of red light slightly more (Figure $5 \mathrm{~K}$ ). Surprisingly, sated Gr64f $>$ GtACR1 flies avoided a range of green light intensities, including a strong aversion to $92 \mu \mathrm{W} / \mathrm{mm}^{2}$ (Figure $5 \mathrm{~J})$. However, hungry Gr64f $>G t A C R 1$ flies were indifferent to green light. These results confirm that emotional responses to anion channelrhodopsin conductance in gustatory cells are distinct from responses to activator photochannels, verifying that GtACR1 is an inhibitor of neuronal activity. This experiment also demonstrates the utility of an optogenetic inhibitor to understanding how tonic activity and quiescence contribute to behavior.

\section{Inhibition of the mushroom body with GtACR1 suppresses short term memory performance}

Synaptic transmission from the Kenyon cells of the mushroom body is required for normal olfactory short term memory (STM) (McGuire, Le, and Davis 2001; Dubnau et al. 2001; Yildizoglu et al. 2015). We hypothesized that GtACR-induced inhibition of the Kenyon cells would compromise fly performance during STM tests. We subjected Drosophila expressing GtACR1 under the control of a mushroom body-specific driver (OK107-Gal4) to aversive olfactory conditioning first under infra-red, and then green light. In all genotypes, exposing flies to infrared light during the first training cycle allowed the formation and expression of robust STM (Figure 6B-F). In $O K 107>e N p H R$ flies, bright amber light $\left(1.7 \mathrm{~mW} / \mathrm{mm}^{2}\right)$ reduced STM performance, however control animals were similarly affected by the light, suggesting marginal inhibition by eNpHR action (Figure 6B). Heat treatment of flies had minor effects on controls, but produced robust STM inhibition in OK107>shits animals (Figure 6C). Subjecting $O K 107>G t A C R 1$ flies to green light produced a robust inhibition of performance, with negligible effects on control lines (Figure 6D-F) across a range of intensities. These data confirm that GtACR1 has similar efficacy for inhibiting central brain neurons as the current standard thermogenetic tool. 
A
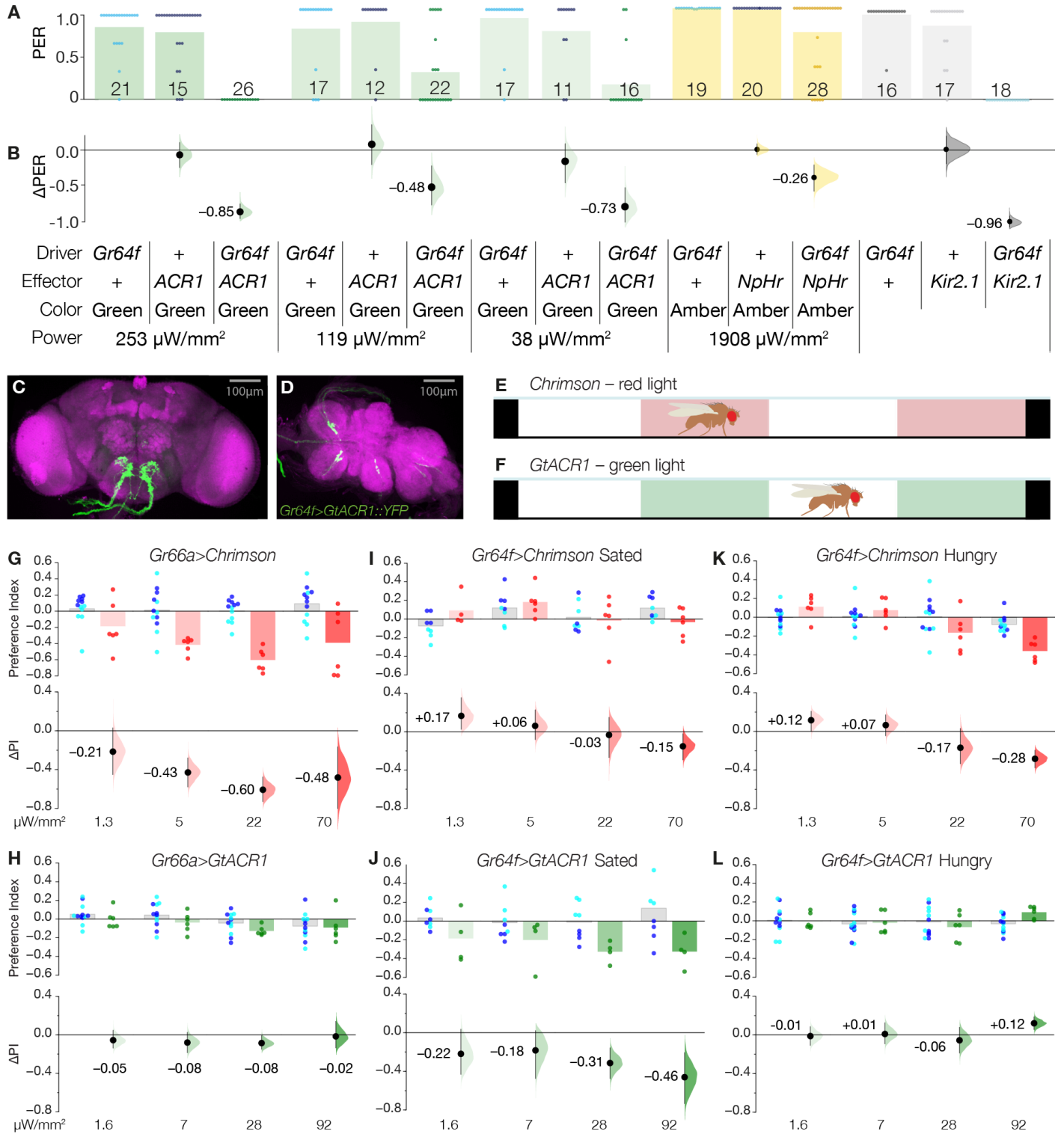

Figure 5. Optogenetic inactivation of taste neurons suppresses proboscis extension reflexes and flies avoid suppression of sweet taste receptors.

A. Proboscis extension responses of transgenic flies exposed to a range of protocols aimed at silencing the Gr64f cells. Dots show individual animal response probabilities, bars represent mean response PER probabilities, numerals indicate sample sizes. Genotypes and conditions are given in key.

B. Changes in responses ( $\triangle P E R$ ) relative to Gr64f-Gal4/+ controls. Illumination of Gr64f>GtACR1 flies produced effective suppression of PER at two weaker light intensities and complete suppression at the highest intensity. Flies expressing UAS-eNpHr in Gr64f-Gal4 showed only a modest reduction in PER in intense amber light $\left(1908 \mu \mathrm{W} / \mathrm{mm}^{2}\right)$. Inhibition of Gr64f neurons with Kir2.1 led to a dramatic reduction in PER as compared to controls. The mean differences are as follows: Gr64f>GtACR1 at $253 \mu \mathrm{W} / \mathrm{mm}^{2} \triangle \mathrm{PER}=-0.85[95 \mathrm{Cl}-1.02,-0.64], P=3.5 \times 10^{-08} ; 119 \mu \mathrm{W} / \mathrm{mm}^{2}$ $\triangle$ PER $=-0.48[95 \mathrm{Cl}-0.21,-0.71], P=1.9 \times 10^{-03} ; 38 \mu \mathrm{W} / \mathrm{mm}^{2} \Delta \mathrm{PER}=-0.73[95 \mathrm{Cl}-0.49,-0.94], P=1.7 \times$ 10-05; Gr64f>eNpHr $\triangle \mathrm{PER}=-0.26[95 \mathrm{Cl}-0.42,-0.12], P=0.054$ and Gr64f>Kir2.1 $\triangle \mathrm{PER}=-0.96[95 \mathrm{Cl}$ $-1.0,-0.92], P=2.7 \times 10^{-08}$.

C-D. The morphology of Gr64f>GtACR1::YFP neurites in the brain and ventral nerve cord. Magenta indicates neuropil stained with anti-DLG, green indicates YFP fluorescence.

E-F. To examine neuronal activation preference (valence) in CsChrimson-bearing flies, a chamber was illuminated with two bands of red light. Diagram not to scale. Valence responses of GtACR1-bearing flies were examined in a chamber illuminated with bands of green light. 


\section{Figure 5 continued.}

G. Flies expressing CsChrimson in their bitter taste neurons (Gr66a>CsChrimson, red dots) were tested for their preference for red light (Gr66a/+, blue dots; UAS-CsChrimson/+, cyan dots), measured as a preference index (PI). The projector light intensities were: 1.3, 5, 22 and $70 \mu \mathrm{W} /$ $\mathrm{mm}^{2}$, left to right. Each dot indicates an experimental iteration, i.e. $\mathrm{N}=\geq 4$; each iteration used 15 flies. Lower panel: Preference relative to control animals $(\Delta \mathrm{PI})$ was calculated as the mean difference between experimental and control PI scores: Gr66a>CsChrimson flies avoided activation at all intensities. At $22 \mu \mathrm{W} / \mathrm{mm}^{2} \Delta \mathrm{PI}=-0.61$ [95Cl $\left.-0.47,-0.73\right], \mathrm{P}=0.0009$.

H. Flies expressing GtACR1 in their bitter taste neurons (Gr66a>GtACR1) had green light preferences that were similar to control animals, at all intensities $\left(1.6,7,28,92 \mu \mathrm{W} / \mathrm{mm}^{2}\right.$, left to right).

I. In a sated state, flies expressing CsChrimson in sweet taste neurons (Gr64f>CsChrimson) showed a modest attraction for $1.3 \mu \mathrm{W} / \mathrm{mm}^{2}$ red light, $\Delta \mathrm{PI}=+0.17[95 \mathrm{Cl} 0.03,+0.37], P=0.10$, and a mild avoidance of $70 \mu \mathrm{W} / \mathrm{mm}^{2}$ red light $\Delta \mathrm{PI}=-0.15[95 \mathrm{Cl}+0.02,-0.29], P=0.11$.

J. In a sated state, flies expressing GtACR1 in sweet taste neurons (Gr64f>GtACR1) avoided green light at a variety of intensities, including strong avoidance at the highest intensity, $\Delta \mathrm{PI}=-0.46$ [95Cl-0.19, -0.73], $P=0.05$.

K. In a hungry state, flies expressing CsChrimson in sweet taste neurons (Gr64f>CsChrimson) showed a similar overall response profile as the sated flies, but showed stronger avoidance at the higher intensities.

L. Hungry flies expressing GtACR1 in sweet tasted neurons were largely indifferent to green light, though were mildly attracted to the highest intensity $\Delta \mathrm{PI}=+0.12[95 \mathrm{Cl}+0.05,+0.19], \mathrm{P}=0.01$.

\section{The GtACRs are minimally toxic}

We sought to estimate the toxicity of GtACR expression and/or activation. The expression of GtACRs in corazonin neurons had little to no effect on neuronal morphology, even after 6 days of continual light exposure (Figure 7A-I). Expression of GtACRs in fly ommatidia with light exposure throughout metamorphosis had no effect on eye morphology (Figure 7G-H). Moreover, broad expression of GtACRs in cholinergic neurons with intermittent light exposure did not dramatically shorten lifespans relative to controls (Figure 7J-K).

\section{Discussion}

The Guillardia theta anion-conducting channelrhodopsins are highly effective tools for the optogenetic inhibition of behavioral circuits in freely-moving animals. The present data reveal that the GtACRs have comparable potency with widely used transgenic and thermogenetic neuronal inhibitors, with temporal precision similar to that of optogenetic activators. For example, the GtACRs have comparable efficacy to $s h i^{i s}$ (Figure 6), but are much faster (Figure 1G)(Kitamoto 2001). We have shown that the GtACRs are more potent than the chloride pump eNpHR, which requires very strong light intensities (Wu et al. 2014; Inada et al. 2011). Indeed, GtACR1 is so effective that intensities as low as $119 \mu \mathrm{W} / \mathrm{mm}^{2}$ can elicit immobilization in a fraction of $U A S-G t A C R 1 /+$ control flies, necessitating calibration of light power. Millisecond-scale, complete paralysis was seen in Cha $>$ GtACR1 flies at power as low as $38 \mu \mathrm{W} / \mathrm{mm}^{2}$ (Figure $1 \mathrm{G}$ ), while no immobilization was observed in UAS-GtACR1/+ with light as strong as $92 \mu \mathrm{W} / \mathrm{mm}^{2}$ (Figure $2 \mathrm{~J}$ ). This makes $38-92 \mu \mathrm{W} / \mathrm{mm}^{2}$ the recommended light range for adult Drosophila experiments with GtACR1. For GtACR2, we recommend $\sim 391 \mu \mathrm{W} / \mathrm{mm}^{2}$, a blue light power that had no visible effect on control UAS-GtACR2/+ animals 
while eliciting fast and complete cholinergic paralysis in Cha>GtACR2 flies (Figure 1J). In practical terms, this means GtACR1 can be actuated with a projector, while GtACR2 requires LED arrays for most freely moving adult Drosophila applications. The GtACRs represent a dramatic improvement over existing methods, orders of magnitude faster than the thermogenetic tools and greatly more potent than eNpHR. The GtACRs are an important addition to the optogenetic toolkit and make neural activity necessity tests as accessible as sufficiency tests are now. * $^{*}$

\section{Methods}

\section{Transgenes, fly strains and rearing conditions}

Drosophila melanogaster flies were used in all experiments. ChATGal4.7.4 (BL 6798) (Salvaterra and Kitamoto 2001), Burs-Gal4 (BL 40972)(Peabody et al. 2008), 20x-UAS-eNpHr3 (BL 36350) (Petersen and Stowers 2011), 20x-UAS-CsChrimson (BL 55134) (Klapoetke et al. 2014), Gr64f-Gal4 (BL 57699) (Weiss et al. 2011), were obtained from the Bloomington Drosophila Stock Center. OK107Gal4 (DGRC 106098) (Connolly et al. 1996) was obtained from the Kyoto Stock center. GMR-Gal4 flies was a gift from Gerry Rubin (Freeman 1996). Crz-Gal4 was a gift from Jay Park (Choi, Lee, and Park 2006). $w^{1118}$ flies were used as wild-type controls in all experiments. To generate UAS-GtACR1 and UAS-GtACR2 transgenic lines, Drosophila-codon-optimized sequences of GtACR1 and GtACR2 (Govorunova et al. 2015) were synthesized de novo (GenScript Pvt. Ltd) as EYFP fusions and subcloned into pJFRC7-20X$U A S-I V S-m C D 8:: G F P$, acquired from Addgene (addgene.org, plasmid \#26220) (Pfeiffer et al. 2010) by replacing the $m C D 8: G F P$ fragment with GtACR1-EYFP or GtACR2-EYFP fragments, followed by sequence verification (GenScript). Constructs were injected into an attP2 insertion site on the third chromosome, and the transgenic progeny were balanced (BestGene Inc.). Expression of the GtACR constructs was verified by YFP fluorescence. For adult fly experiments, 3-4 days old male flies were fed with $1 \mathrm{mM}$ all-transretinal (Sigma) for 2-3 days at $25^{\circ} \mathrm{C}$ in the dark. A stock solution of all-trans-retinal was prepared in 95\% ethanol (w/v) and mixed in with warm and liquefied fly food. Each vial was covered with aluminium foil and placed in the dark.

\section{Optogenetic photoactivation}

Green, blue, red and amber LEDs (LUXEON Rebel LED on a SinkPAD-II 10mm Square Base available from www.luxeonstar.com; green SP-05-G4, peak emission $525 \mathrm{~nm}$; blue SP-05-B4, peak 460nm; red-orange SP-05-E4, peak $617 \mathrm{~nm}$ and pc-amber SP-05-A5, peak $591 \mathrm{~nm}$ ), or an LED micro-projector (Optoma ML750), were placed near behavioral arenas to provide an illumination source. LEDs were powered at maximum brightness by a 700mA BuckPuck driver and illumination intensity was controlled by varying the distance between the source and subject. The PC-controlled LED micro-projector was used to project images consisting of entirely red, 
green or blue backgrounds onto the arena. The projector uses a Digital Light Processing (DLP, Texas Instruments) micromirror device with a refresh rate of $60 \mathrm{~Hz}$. For a consistent environment, the illuminatory and behavioral monitoring system was placed inside the incubator and maintained at $25^{\circ} \mathrm{C}$ throughout the experiment.

A

D
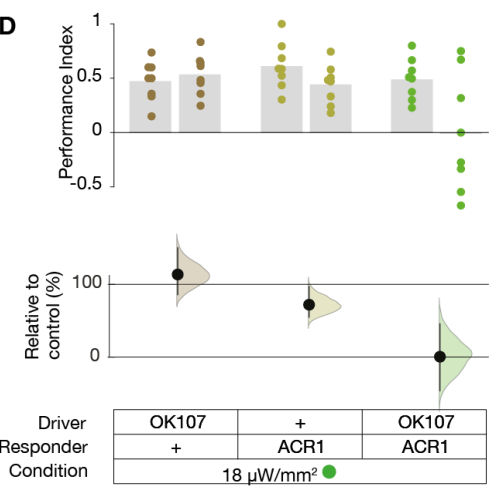
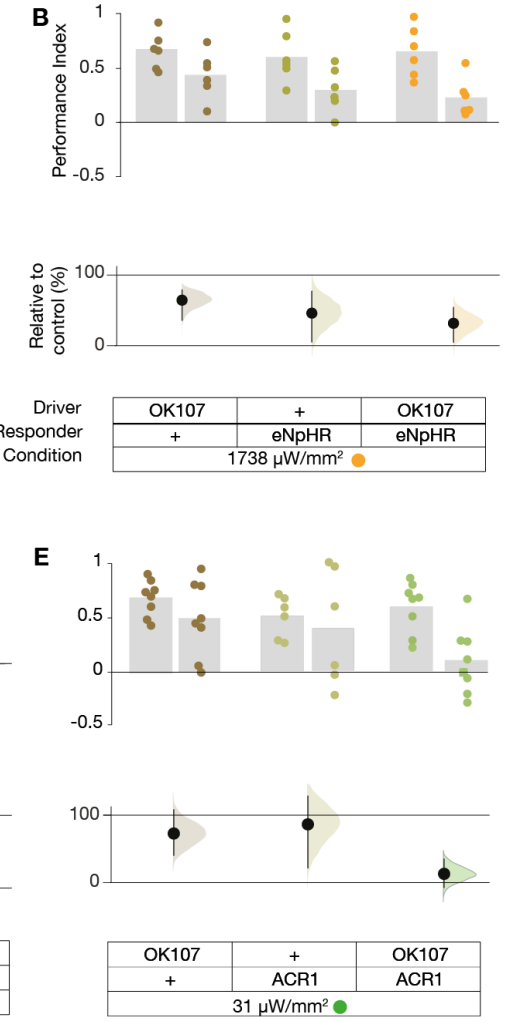
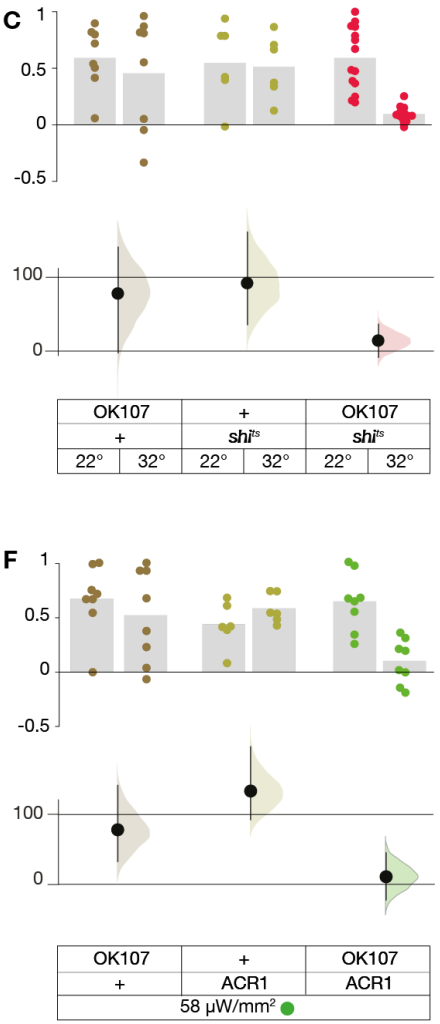

Figure 6. Optogenetic inactivation of Kenyon cells diminishes olfactory short-term memory. A. The expression pattern of UAS-GTACR1::YFP driven with OK107-Gal4. Grey indicates YFP fluorescence.

B. Flies were trained and tested under infrared light in an initial training cycle (left columns) and then trained and retested again under optogenetic light during a second training cycle (right columns). Flies expressing eNpHR in the mushroom body cells (OK107>eNpHR) had a reduction in STM during strong amber illumination, $\Delta \mathrm{PI}=-0.43[95 \mathrm{Cl}-0.71,-0.14], P=0.005$. Howev$\mathrm{er}$, this reduction was only modestly stronger than control animals, suggesting the effect was primarily due to the light alone. Genotype key is at the bottom, colored dots represent the average of two half PIs from 6 animals each, $\mathrm{N}=8$ experiments as indicated by the dots. Lower axis: The memory effects of illumination as a percentage of the same animals' scores under infrared light. Error bars are confidence intervals of the mean; curve is the bootstrap distribution of the mean.

C. Inhibition of OK107 cells with UAS-shits at $32^{\circ} \mathrm{C}$ led to an almost complete block of STM, $\triangle \mathrm{PI}=-$ 0.5 [95Cl-0.67, -0.33$], P=1.4 \times 10^{-05}$. A similar heat treatment of controls produced only trivial effects.

D. Illumination with green light either slightly increased (OK107/+) or decreased (UAS-GtACR1/+) STM performance in control animals. However, green light illumination at $18 \mu \mathrm{W} / \mathrm{mm}^{2}$ reduced STM performance in flies expressing OK107-Gal4>UAS-GtACR1. $\triangle \mathrm{PI}=-0.50[95 \mathrm{Cl}-0.97,-0.1], P=$ 0.03 .

E. Illumination of $O K 107>$ GtACR 1 flies with $31 \mu \mathrm{W} / \mathrm{mm}^{2}$ green light also inhibited the expression of STM $\triangle \mathrm{PI}=-0.5[95 \mathrm{Cl}-0.33,-0.66], P<0.001$.

F. Illumination of $O K 107>G t A C R 1$ flies with $58 \mu \mathrm{W} / \mathrm{mm}^{2}$ light inhibited conditioned avoidance $\triangle \mathrm{PI}$ $=-0.55[95 \mathrm{Cl}-0.31,-0.76], P=0.003$. 


\section{Video acquisition}

Videos were captured at 30 frames per second using an AVT Guppy F-046B CCD camera (Stemmer Imaging, UK), equipped with a 12 mm CCTV-type lens and connected to a computer via an IEEE 1394 cable. Experiments were conducted under infrared (IR) light; an IR longpass filter (Edmund Optics, Singapore) was used to reduce de-
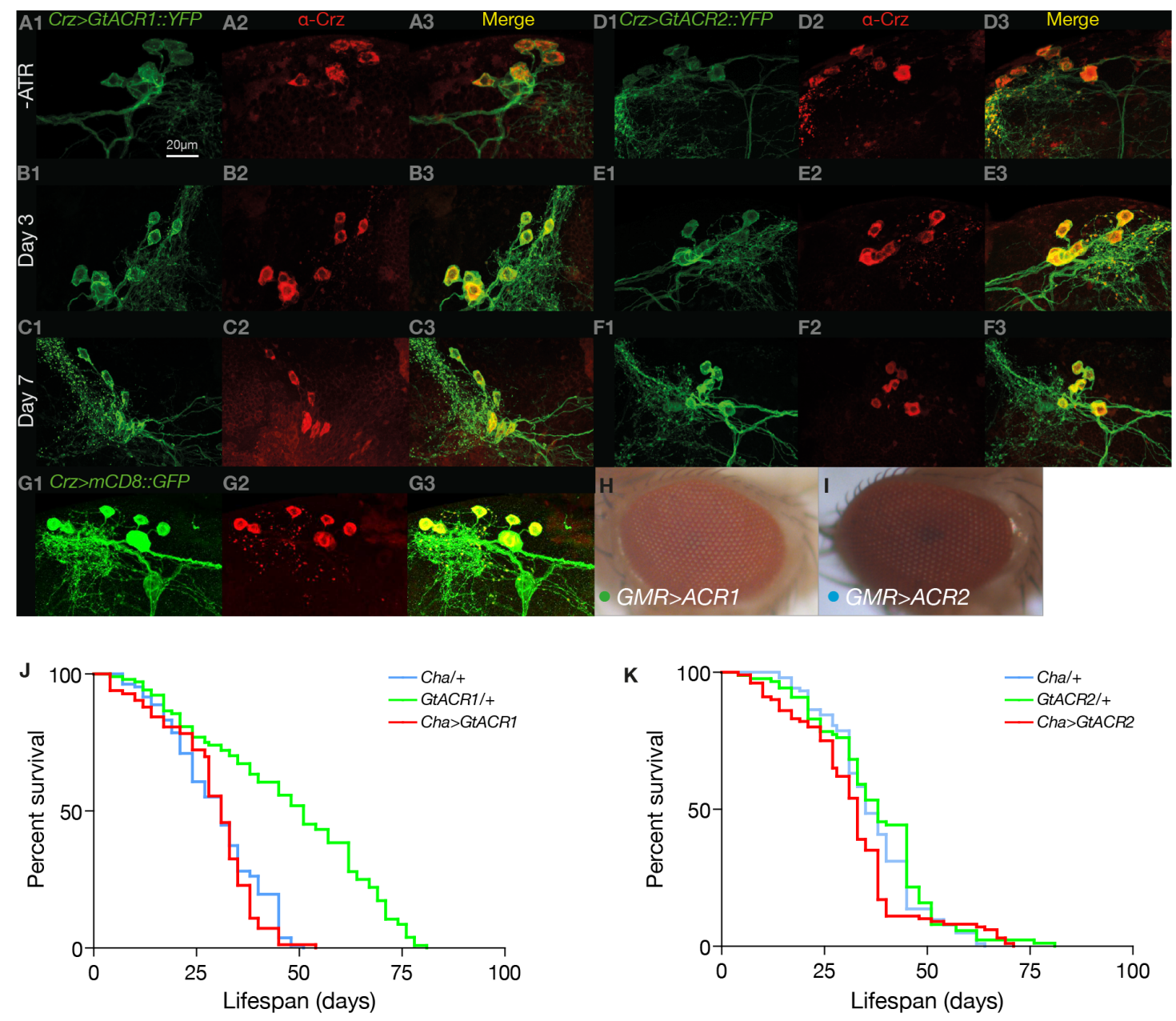

Figure 7. GtACRs have minimal toxicity.

A1. Central brain cells were observed to express yellow fluorescent protein-tagged GtACR1 (green, endogenous fluorescence) in Crz>GtACR1 fly brains prior to all-trans-retinal (ATR) feeding.

A2-3. Antibody staining for $\mathrm{Crz}$ protein ( $\alpha$ - $\mathrm{Crz}$, red) confirmed GtACR1-expressing cells were $\mathrm{Crz}^{+}$.

B1-3. Crz+ cell morphology was normal in Crz>GtACR1 flies after ATR feeding and one day of illumination with $19 \mu \mathrm{W} / \mathrm{mm}^{2}$ green light.

C1-3. Crz+ cell morphology was normal in Crz>GtACR1 flies after ATR feeding, 6 days of illumination. D-F. Flies expressing GtACR2::YFP in Crz cells had normal morphology after 6 days of GtACR2 activation with $25 \mu \mathrm{W} / \mathrm{mm}^{2}$ blue light.

G. The morphology of cells carrying a fluorescent protein (mCD8::GFP) but no photochannel. The mCD8::GFP was visualized with anti-GFP antibody, thus appears brighter.

H-I. Flies expressing either GtACR1 or GtACR2 with the GMR-Gal4 driver had normal eye morphology after being illuminated during metamorphosis.

J. The lifespans of flies bearing Cha>GtACR 1 transgenic expression (median $=31$ days $[95 \mathrm{Cl} 28,33]$ ) were similar to Cha-Gal4/+ controls (median $=35$ days $[95 \mathrm{Cl} 33,40]$ ), and shorter than the lifespans of GtACR1/+ animals (median = 51 days $[95 \mathrm{Cl} 45,57]$ ). All flies were subjected to intermittent ad hoc light exposure.

K. The lifespans of flies with Cha>GtACR2 transgenic expression (median $=31$ days $[95 \mathrm{Cl} 28,33]$ ) were similar to $\mathrm{Cha}-\mathrm{Gal} 4 /+($ median $=31$ days $[95 \mathrm{Cl} 27,33])$ and $\mathrm{GtACR} 2 /+($ median $=38$ days $[95 \mathrm{Cl}$ $33,45])$ controls. 
tection of the micro-projector/LED light. Custom-built image acquisition software CRITTA, written in LabView (National Instruments, USA), was used to track the movements of animals in the behavioral arenas.

\section{Light intensity measurements}

The light intensities of the projector and LED illumination were measured for all wavelengths for every configuration used in the experiments: number of LEDs, distance from chamber, type of lens and projector DLP intensity values. A thermal power sensor (Thorlabs S310C) connected to a power and energy meter console (Thorlabs PM100D) was used to measure power in a dark room. The meter was zeroed before each set of measurements and a cardboard shield with a $20 \mathrm{~mm}$ diameter cutout was used to ensure light only struck the sensor's absorbent surface.

\section{Falling assay}

Fly climbing/locomotion performance was monitored in a custom acrylic arena. Four ATR treated flies, cooled on ice were transferred into each arena. The climbing was performed in a rectangular arena $(70 \times 11 \mathrm{~mm}), 4$ such arenas were cut into a $1.5 \mathrm{~mm}$ thick transparent acrylic sheet that was incorporated into a transparent acrylic 'sandwich'. Climbing behavior was recorded under IR backlighting. The arena sandwich was illuminated from the front by DLP projector. Flies were allowed to freely explore the arena during the test session. The behavior of flies illuminated with IR, green, blue and red light was recorded. For higher intensity, the projector was placed closer to the behavioral arena. For the duration of the test, flies were individually tracked using a monochrome camera connected to CRITTA tracking software which also controlled the timing, hue and intensity of the illumination by driving the projected image. As well as recording the vertical position of each fly, the software divided the chamber into two zones, the lower 5.5\% and the upper $94.5 \%$ and the number of flies occupying each zone was logged. Fully paralysed flies fell to the bottom of the chamber, occupied the lower zone and were scored as fallen.

\section{Walking paralysis}

A Guppy F-046B camera was used to record fly behavior at 25 frames per second in stadium-shaped arenas $(55 \times 4 \times 1.5 \mathrm{~mm})$; fifteen such arenas were cut from acrylic. Cha>CsChrimson, Cha $>$ GtACR1, Cha $>$ GtACR2, and control flies were illuminated with a DLP projector. CRITTA and Python scripts were used to analyze walking speeds and generate the Muybridge series.

\section{High frame-rate video analysis of walking paralysis}

High frame video was recorded at 1000 frames per second using a Photron FASTCAM MC2 Camera, was conducted to quantify the onset of inhibition and recovery with high temporal accuracy. For each genotype studied, 4 flies were anesthetized on ice and loaded 
into 4 separate clear acrylic chambers measuring $9 \times 9 \times 1.5 \mathrm{~mm}$ and covered by a microscope cover slip. For GtACR recordings the chamber was front-illuminated by a red-filtered fiber optic light source and for eNpHR, which is known to be sensitive to red light, IR backlighting was used. Before recording fly locomotion was elicited by shaking the chamber. Red, green, blue or amber LEDs, set at varying distances from $3 \mathrm{~mm}$ to $330 \mathrm{~mm}$ from the subject, were turned on manually when the fly was freely walking and turned off several seconds after paralysis occurred. The video buffer was limited to 16 seconds, and the illumination duration was typically $2 \mathrm{~s}$, though prolonged to a maximum of $30 \mathrm{~s}$ if no effect was seen. Videos were analysed offline by visual inspection to determine the frame where flies were first immobilized, defined as when forward locomotion is abated (though some movement may still occur due to momentum or gravity); the frame containing the first sign of recovery, e.g. the movement of a leg; and the first frame where the fly has recovered, is fully mobile and begins walking away. In addition, the frames where the light is turned on and off were marked and then the following timings were calculated: time from light onset to immobilization, time from light-off to first recovery and time from light-off to re-mobilization. Pixel difference data was analyzed with custom scripts in LabVIEW and Python.

\section{Wing expansion assay}

For wing expansion experiments, larvae were fed with $200 \mu \mathrm{M}$ alltrans-retinal (ATR) throughout larval development. At 1-2 days after puparium formation (APF), pupae were transferred to green, blue or red light conditions at $25^{\circ} \mathrm{C}$. Flies remained under this light until 9-10 days APF, when wing expansion was scored under a dissection microscope. For Kir2.1, all flies were raised at $18^{\circ} \mathrm{C}$ until 1-2 days APF, pupae were transferred to either $18^{\circ} \mathrm{C}$ or $31^{\circ} \mathrm{C}$ for Tub-Galso ${ }^{\text {ts }}$ de-repression of Kir2.1 expression. Wing expansion was scored under a dissection microscope until 9-10 days APF.

\section{Olfactory short term memory}

Aversive olfactory conditioning of Drosophila was performed in custom-built chambers modified from a previously described single-fly olfactory trainer apparatus (Claridge-Chang et al. 2009). To allow light penetration and video monitoring of multiple flies, windows were cut into the top and bottom of each chamber. The floor and ceiling of each chamber was a glass slide printed with transparent indium tin oxide (ITO) electrode boards (Visiontek UK) (Vogt et al. 2014). Each side of the ITO board was sealed by a gasketed lid that formed a seal around the gap between the ITO board and the chamber wall. The internal behavioral arena measured $50 \mathrm{~mm}$ long, $5 \mathrm{~mm}$ wide and $1.3 \mathrm{~mm}$ high. Mirrors were aligned at a $45^{\circ}$ angle and placed into holders on top of each chamber. Facilitated by carrier air, odors entered each end of the chamber via two entry pipes and left the chamber through two vents located in the middle of the chamber. Flies were conditioned using electric shocks (12 electric shocks 
at $60 \mathrm{~V}$ ) that were through the circuit boards. At the start of each conditioning experiment the flies were iced in darkness and loaded into the chambers, 6 flies per chamber. Experiments were performed with four chambers simultaneously that were plugged into a rack in a $2 \times 2$ manner. Throughout the conditioning cycle, Drosophila flies were entrained to either avoid 3-octanol (OCT) or 4-methylcyclohexanol $(\mathrm{MCH})$. Conditioning performance was tested by exposing one half of the chamber to the punished odor and the other half to the unpunished odor. A performance index (PI) was calculated by counting flies in individual video frames over the last 30 s of assessment, using a formula described previously (Quinn, Harris, and Benzer 1974). After the initial conditioning cycle, the same organisms were entrained to the same odor again by using an identical protocol except that green $(\lambda 525 \mathrm{~nm})$ or amber light $(\lambda 591 \mathrm{~nm})$ was turned on during memory retrieval. In shits experiments, all flies were initially conditioned at $22^{\circ} \mathrm{C}$ and subsequently incubated for 30 minutes at $32^{\circ} \mathrm{C}$ to inactivate endocytosis. After the incubation period, the flies were conditioned against the same odor a second time at $22^{\circ} \mathrm{C}$. Finally, the fly performance between the first and second conditioning cycle was compared.

\section{Optogenetic valence assay}

Each arena had a $55 \times 4 \mathrm{~mm}$ stadium layout; 15 such arenas were cut from $1.5 \mathrm{~mm}$ thick transparent acrylic. During an experiment, all arenas were covered with a transparent acrylic lid. Ice-anesthetized flies were loaded into each chamber in dark and the whole arena was kept under infrared light at $25^{\circ} \mathrm{C}$ for $2-3$ minutes before starting the assay; behavior was recorded under IR lighting. The arena was illuminated from the top with visible light from a mini-projector (Optoma ML750). For CsChrimson experiments, four red light intensities were used; for $A C R$ experiments, green light four green light intensities was used. The coloured light intensity was varied by changing the level of the respective digital color components of the projection. For each batch of experiments, two light-test sessions were conducted, separated by 10s. For the first test session, the arenas were illuminated for 60 seconds with stripes consisting of two light and two dark zones, all equally sized. For the second 60 second test session the locations of the light and dark zones were reversed. For the duration of the test, the positions of the flies were individually tracked using a Guppy F-046B camera with an IR bandpass filter, connected to CRITTA tracking software which also controlled the timing, hue and intensity of the illumination by driving the projected image, as well as counting the number of flies in each zone. Fly preference for light was calculated as a preference index by subtracting the total number of flies in the dark from the total number of flies in the light, and dividing this number by the total number of flies in the experiment, for each of the 4 light intensities. 


\section{Proboscis extension reflex assay}

In all experiments, $4-5$ days old, $30 \mathrm{hr}$ wet-starved (0.5\% agarose) male flies were used. Each fly was glued by its back onto a glass slide with nail polish, then placed in a vial with a water-soaked tissue to recover for 1-2 hours. The PER response was tested by manually presenting a drop of $1 \mathrm{M}$ sucrose solution (Sigma) to the forelegs for up to $5 \mathrm{sec}$, using a $1 \mathrm{ml}$ syringe, in the presence of red or green or amber light. When the fly extended its proboscis, the syringe was immediately withdrawn to prevent drinking. GtACR flies were tested with red, green and blue; eNpHR was tested with high intensity amber. Flies were given water before the experiment and after each light change. Light color was randomized for each fly. Each presentation was recorded manually. Fly responses were counted offline manually. Each fly was tested 3 times, and responses were counted as either 0 or 1 (for the absence and presence of PER respectively): the mean outcome of 3 presentations was denoted as fly performance. $\triangle$ PER values for each condition were calculated by subtracting PER performance of the driver controls from the PER response of responder control and experimental animals.

\section{Survival analysis and toxicity assays}

We performed survival assays of flies expressing GtACRs in all cholinergic neurons using Cha-Gal4 after treatment with ATR for 4 days. Animals were briefly exposed to light at day 4, 7 and 12 after eclosure. Throughout the assay, Drosophila were transferred into new food vials every third day and any deaths were recorded; longevity was monitored until all flies were dead. To examine GtACR cellular toxicity, we expressed GtACRs in retinal cells with the Glass Multiple Reporter GMR-Gal4 driver and examined the offspring for rough-eye phenotypes (Van Vactor et al. 1991). Larvae were kept in the dark on ATR food throughout development. Pupae were exposed to light from 2-3 days after pupal formation until eclosion, and eyes were examined 5 days after eclosion. To monitor toxicity in central brain cells, we expressed GtACR::YFP in Corazonin (Crz) cells with $\mathrm{Crz}$-Gal4 which expresses in 6-8 neurons (Choi, Lee, and Park 2006). After eclosion, flies were transferred to the ATR treated food for 2-3 days. Brains were dissected at three stages: before ATR treatment, 1 day after ATR treatment with light exposure and 6 days after ATR with light exposure.

\section{Immunohistochemistry}

Adult brains were dissected in PBS and fixed in 4\% paraformaldehyde for $20 \mathrm{~min}$ at room temperature. Samples were washed three times in PBT (phosphate buffered saline with $1 \%$ Triton X-100 at pH 7.2 ) and blocked with $5 \%$ normal goat serum for one hour. Samples were then incubated with primary antibodies overnight at $4^{\circ} \mathrm{C}$. After three additional washes with PBT, samples were incubated with a secondary antibody overnight at $4^{\circ} \mathrm{C}$. Stained brains were mounted in Vectashield (Vector Laboratories, Burlingame, CA, USA) and recorded with confocal fluorescence laser scanning microscopy 
(Zeiss). Anti-Crz antibody (1:1000) and goat anti-rabbit-Alexa Fluor 568 (A-11011, Molecular Probes, 1:200 dilution) were used. GtACR1::YFP and GtACR2::YFP were visualized without antibody staining. Control mCD8::GFP expression was visualised using antiGFP (ab13970) and anti-chicken-Alexa Fluor 488 antibody staining.

\section{Electrophysiology}

Third instar larvae were dissected in HL3 solution modified from a previous recipe as follows: $110 \mathrm{mM} \mathrm{NaCl}, 5 \mathrm{mM} \mathrm{KCl}, 5 \mathrm{mM} \mathrm{HEP-}$ ES, $10 \mathrm{mM} \mathrm{NaHCO} 3,5 \mathrm{mM}$ trehalose, $30 \mathrm{mM}$ sucrose, $1.5 \mathrm{mM}$ $\mathrm{CaCl}_{2}, 4 \mathrm{mM} \mathrm{MgCl}$ (Verstreken et al. 2003). An individual abdominal nerve (A 3/4) was drawn into a fire-polished glass suction electrode as described previously (Tracey et al. 2003). Extracellular recordings of action potentials from both sensory and motor neurons were performed using a DAM-50 Differential Amplifier (World Precision Instruments) in the AC mode at $1000 \times$ gain and bandpass filtered at $100 \mathrm{~Hz}-1.5 \mathrm{kHz}$. Optogenetic silencing of the segmental nerve was achieved using $500 \mathrm{~ms}$ and $30 \mathrm{~s}$ pulses of light from a green LED triggered from the Clampex software (Molecular Devices) during recordings. Spiking activity occurred in bouts separated by intervals of quiescence; after recording, if no spiking was observed prior to light onset, that epoch's data were excluded from the analysis. Spike detection was performed using a window discriminator (Meliza and Margoliash 2012). A spike was defined as an upward signal that peaked within $50 \mathrm{~ms}$, and had an amplitude threshold of 2.58 standard deviations from the mean amplitude. The spiking frequency of each nerve was calculated with a rolling window of $100 \mathrm{~ms}$ and $500 \mathrm{~ms}$, for $500 \mathrm{~ms}$ and $30 \mathrm{~s}$ illumination pulses respectively.

\section{Statistics and analysis}

Estimation statistical methods were used to analyze and interpret quantitative data (Altman et al. 2000; Claridge-Chang and Assam 2016; Cumming 2012). For each olfactory STM experiment, the mean difference in PI for green light (relative to IR light) was computed $(\triangle \mathrm{PI})$. For each PER experiment, the mean difference in PER scores relative to driver controls was computed $(\triangle \mathrm{PER})$. Data were presented as mean difference contrast plots (Gardner and Altman 1986; Cumming 2012). Bootstrap methods (Efron 1979) were used to calculate $95 \%$ confidence intervals for the mean difference between control and experimental groups. Confidence intervals were bias-corrected and accelerated (DiCiccio and Efron 1996), and were displayed with the bootstrap distribution of the mean; resampling was performed 2,000 times. All reported $P$ values are the results of two-tailed Student $t$-tests. Data analysis was performed and visualized in LabVIEW, in Matlab, and in Python using Jupyter and the scikits-bootstrap, seaborn, and SciPy packages.

\section{Author Contributions}

Conceptualization: FM and ACC; Methodology: FM, JCS and ACC; Software: JCS (CRITTA, Labview) and JH (Python); Investigation: 
FM (transgene design, genetics, paralysis, wing expansion, toxicity in eyes, proboscis extension reflex, valence, neuroanatomy), SO (learning and survival), JCS (paralysis), JYC (brain dissection, immunohistochemistry, microscopy) and KC (proboscis extension reflex), TWK (extracellular recordings); Resources: JCS (instrumentation); Data Analysis: JH (valence, electrophysiology), KC (PER), JCS (paralysis, falling), SO (STM) and FM (paralysis, valence, anatomy); Writing - Original Draft: FM and ACC; Writing - Revision: FM, SO, JCS and ACC; Visualization: FM, JH, JCS, SO, KC and ACC; Supervision: ACC; Project Administration: ACC; Funding Acquisition: ACC.

\section{Acknowledgements}

We thank John Spudich for providing the GtACR1 and GtACR2 sequences and plasmids. We thank Jan Adrianus Veenstra for the anti-Crz antibody. We thank Sherry Aw for loan of the high-speed camera. We thank George Augustine for comments on the manuscript. We thank Lucy Robinson of Insight Editing London for editing of the manuscript. FM, SO, JYC and ACC were supported by grant MOE-2013-T2-2-054 from the Ministry of Education; JCS and ACC were supported by grants 1231AFG030 and 1431AFG120 from the A*STAR Joint Council Office. JH was supported by the A*STAR Graduate Academy. The authors were supported by a Biomedical Research Council block grant to the Institute of Molecular and Cell Biology. FM, SO, KC and ACC received support from Duke-NUS Medical School, including the Integrated Biology and Medicine doctoral program (KC). 


\section{Video Legends}

\section{Video 1. GtACR flies fall from a vertical surface when illuminated}

Flies expressing one of three optogenetic inhibitors in their cholinergic neurons (Cha-Gal4>UASGtACR1, Cha-Gal4>UAS-GtACR2 and Cha-Gal4>UAS-eNpHR) were illuminated with light from a projector. Cha>GtACR1 and Cha>GtACR2 flies fell from the vertical acrylic surface upon exposure to green or blue light respectively, and were immobilized. Cha>GtACR2 flies retained some motor activity while illuminated with blue light. Cha>eNpHR flies did not fall upon exposure to red light and remained mobile.

\section{Video 2. GtACR flies are immobilized by illumination}

A. Green light at $38 \mu \mathrm{W} / \mathrm{mm}^{2}$ rendered a Cha>GtACR1 fly immobile, though it regained some motor control during illumination. Green dot indicates when light was turned on.

B. Illumination of a GtACR1/+ fly with $38 \mu \mathrm{W} / \mathrm{mm}^{2}$ green light had no effect.

C. A Cha>GtACR2 fly was rendered completely paralyzed by illumination with $391 \mu \mathrm{W} / \mathrm{mm}^{2}$ blue light. Blue dot indicates when light was turned on.

D. A GtACR2/+ fly was unaffected by illumination with $391 \mu \mathrm{W} / \mathrm{mm}^{2}$ blue light.

E. While positioned $3 \mathrm{~mm}$ above an amber LED (approximately $1.9 \mathrm{~mW} / \mathrm{mm}^{2}$ ), a Cha>eNpHR fly retained mobility, though it was paralyzed transiently when passing directly above the emitter. Light was on throughout this recording.

F. A Cha>eNpHR fly was unaffected by amber illumination at $495 \mu \mathrm{W} / \mathrm{mm}^{2}$. Amber dot indicates when light was on.

Video 3. Cha>GtACR and Cha>CsChrimson flies have distinct responses to actuation.

Cha>GtACR flies adopt a static pose during illumination (indicated by colored dots), but Cha>Chrimson flies have active seizures and adopt a tetanic pose with extended wings. Control animals were unaffected by projector light (green $92 \mu \mathrm{W} / \mathrm{mm}^{2}$; blue $67 \mu \mathrm{W} / \mathrm{mm}^{2}$; red $70 \mu \mathrm{W} /$ $\mathrm{mm}^{2}$ ). 


\section{References}

Altman, D., D. Machin, T. Bryant, and S. Gardner. 2000. "Statistics with Confidence: Confidence Interval and Statistical Guidelines." Bristol: BMJ Books.

Aso, Yoshinori, Divya Sitaraman, Toshiharu Ichinose, Karla R. Kaun, Katrin Vogt, Ghislain Belliart-Guérin, Pierre-Yves Plaçais, et al. 2014. "Mushroom Body Output Neurons Encode Valence and Guide Memory-Based Action Selection in Drosophila." eLife 3 (December): e04580.

Baines, R. A., J. P. Uhler, A. Thompson, S. T. Sweeney, and M. Bate. 2001. "Altered Electrical Properties in Drosophila Neurons Developing without Synaptic Transmission." The Journal of Neuroscience: The Official Journal of the Society for Neuroscience 21 (5): 1523-31.

Berndt, Andre, Soo Yeun Lee, Charu Ramakrishnan, and Karl Deisseroth. 2014. "StructureGuided Transformation of Channelrhodopsin into a Light-Activated Chloride Channel." Science 344 (6182): 420-24.

Boyden, Edward S., Feng Zhang, Ernst Bamberg, Georg Nagel, and Karl Deisseroth. 2005. "Millisecond-Timescale, Genetically Targeted Optical Control of Neural Activity." Nature Neuroscience 8 (9): 1263-68.

Choi, Youn-Jeong, Gyunghee Lee, and Jae H. Park. 2006. "Programmed Cell Death Mechanisms of Identifiable Peptidergic Neurons in Drosophila Melanogaster." Development 133 (11): 2223-32.

Chow, Brian Y., Xue Han, Allison S. Dobry, Xiaofeng Qian, Amy S. Chuong, Mingjie Li, Michael A. Henninger, et al. 2010. "High-Performance Genetically Targetable Optical Neural Silencing by Light-Driven Proton Pumps." Nature 463 (7277): 98-102.

Claridge-Chang, Adam, and Pryseley N. Assam. 2016. "Estimation Statistics Should Replace Significance Testing." Nature Methods 13 (2): 108-9.

Claridge-Chang, Adam, Robert D. Roorda, Eleftheria Vrontou, Lucas Sjulson, Haiyan Li, Jay Hirsh, and Gero Miesenböck. 2009. "Writing Memories with Light-Addressable Reinforcement Circuitry." Cell 139 (2): 405-15.

Connolly, John B., Ian J. H. Roberts, J. Douglas Armstrong, Kim Kaiser, Michael Forte, Tim Tully, and Cahir J. O'Kane. 1996. "Associative Learning Disrupted by Impaired Gs Signaling in Drosophila Mushroom Bodies." Science 274 (5295). American Association for the Advancement of Science: 2104-7.

Cumming, Geoff. 2012. Understanding the New Statistics Effect Sizes, Confidence Intervals, and Meta-Analysis. New York: Routledge.

DiCiccio, Thomas J., and Bradley Efron. 1996. "Bootstrap Confidence Intervals." Statistical Science: A Review Journal of the Institute of Mathematical Statistics 11 (3). Institute of Mathematical Statistics: 189-212.

Dubnau, J., L. Grady, T. Kitamoto, and T. Tully. 2001. "Disruption of Neurotransmission in Drosophila Mushroom Body Blocks Retrieval but Not Acquisition of Memory." Nature 411 (6836): 476-80.

Efron, B. 1979. "Bootstrap Methods: Another Look at the Jackknife." Annals of Statistics 7 (1): 1-26.

Freeman, M. 1996. "Reiterative Use of the EGF Receptor Triggers Differentiation of All Cell Types in the Drosophila Eye." Cell 87 (4): 651-60.

Gardner, M. J., and D. G. Altman. 1986. "Confidence Intervals rather than P Values: Estimation rather than Hypothesis Testing." British Medical Journal 292 (6522): 746-50.

Govorunova, Elena G., Oleg A. Sineshchekov, Roger Janz, Xiaoqin Liu, and John L. Spudich. 
2015. "Natural Light-Gated Anion Channels: A Family of Microbial Rhodopsins for Ad" vanced Optogenetics." Science 349 (6248): 647-50.

Hamada, Fumika N., Mark Rosenzweig, Kyeongjin Kang, Stefan R. Pulver, Alfredo Ghezzi, Timothy J. Jegla, and Paul A. Garrity. 2008. "An Internal Thermal Sensor Controlling Temperature Preference in Drosophila." Nature 454 (7201): 217-20.

Inada, Kengo, Hiroshi Kohsaka, Etsuko Takasu, Teruyuki Matsunaga, and Akinao Nose. 2011. "Optical Dissection of Neural Circuits Responsible for Drosophila Larval Locomotion with Halorhodopsin." PloS One 6 (12): e29019.

Johns, D. C., R. Marx, R. E. Mains, B. O’Rourke, and E. Marbán. 1999. "Inducible Genetic Suppression of Neuronal Excitability." The Journal of Neuroscience: The Official Journal of the Society for Neuroscience 19 (5): 1691-97.

Kitamoto, T. 2001. "Conditional Modification of Behavior in Drosophila by Targeted Expression of a Temperature-Sensitive Shibire Allele in Defined Neurons." Journal of Neurobiology 47 (2): 81-92.

Klapoetke, Nathan C., Yasunobu Murata, Sung Soo Kim, Stefan R. Pulver, Amanda BirdseyBenson, Yong Ku Cho, Tania K. Morimoto, et al. 2014. "Independent Optical Excitation of Distinct Neural Populations." Nature Methods 11 (3): 338-46.

Knoflach, Frédéric, Maria-Clemencia Hernandez, and Daniel Bertrand. 2016. "GABAA Receptor-Mediated Neurotransmission: Not so Simple after All." Biochemical Pharmacology 115 (September): 10-17.

Lima, Susana Q., and Gero Miesenböck. 2005. "Remote Control of Behavior through Genetically Targeted Photostimulation of Neurons." Cell 121 (1): 141-52.

Mahn, Mathias, Matthias Prigge, Shiri Ron, Rivka Levy, and Ofer Yizhar. 2016. "Biophysical Constraints of Optogenetic Inhibition at Presynaptic Terminals." Nature Neuroscience 19 (4): 554-56.

McGuire, S. E., P. T. Le, and R. L. Davis. 2001. "The Role of Drosophila Mushroom Body Signaling in Olfactory Memory." Science 293 (5533): 1330-33.

Meliza, C. Daniel, and Daniel Margoliash. 2012. "Emergence of Selectivity and Tolerance in the Avian Auditory Cortex." The Journal of Neuroscience: The Official Journal of the Society for Neuroscience 32 (43): 15158-68.

Peabody, Nathan C., Fengqiu Diao, Haojiang Luan, Howard Wang, Elizabeth M. Dewey, Hans-Willi Honegger, and Benjamin H. White. 2008. "Bursicon Functions within the Drosophila CNS to Modulate Wing Expansion Behavior, Hormone Secretion, and Cell Death." The Journal of Neuroscience: The Official Journal of the Society for Neuroscience 28 (53): 14379-91.

Petersen, Lena K., and R. Steven Stowers. 2011. "A Gateway MultiSite Recombination Cloning Toolkit." PloS One 6 (9): e24531.

Pfeiffer, Barret D., Teri-T B. Ngo, Karen L. Hibbard, Christine Murphy, Arnim Jenett, James W. Truman, and Gerald M. Rubin. 2010. "Refinement of Tools for Targeted Gene Expression in Drosophila." Genetics 186 (2): 735-55.

Quinn, W. G., W. A. Harris, and S. Benzer. 1974. "Conditioned Behavior in Drosophila Melanogaster." Proceedings of the National Academy of Sciences of the United States of America 71 (3): 708-12.

Roth, Bryan L. 2016. "DREADDs for Neuroscientists." Neuron 89 (4): 683-94.

Salvaterra, Paul M., and Toshihiro Kitamoto. 2001. "Drosophila Cholinergic Neurons and Processes Visualized with Gal4/UAS-GFP." Gene Expression Patterns: GEP 1: 73-82. 
Sweeney, S. T., K. Broadie, J. Keane, H. Niemann, and C. J. O'Kane. 1995. "Targeted Ex' pression of Tetanus Toxin Light Chain in Drosophila Specifically Eliminates Synaptic Transmission and Causes Behavioral Defects." Neuron 14 (2): 341-51.

Thoma, Vladimiros, Stephan Knapek, Shogo Arai, Marion Hartl, Hiroshi Kohsaka, Pudith Sirigrivatanawong, Ayako Abe, Koichi Hashimoto, and Hiromu Tanimoto. 2016. "Functional Dissociation in Sweet Taste Receptor Neurons between and within Taste Organs of Drosophila." Nature Communications 7 (February): 10678.

Tracey, W. Daniel, Jr, Rachel I. Wilson, Gilles Laurent, and Seymour Benzer. 2003. "Painless, a Drosophila Gene Essential for Nociception." Cell 113 (2): 261-73.

Tye, Kay M., and Karl Deisseroth. 2012. "Optogenetic Investigation of Neural Circuits Underlying Brain Disease in Animal Models." Nature Reviews. Neuroscience 13 (4): 251-66.

Van Vactor, D. L., Jr, R. L. Cagan, H. Krämer, and S. L. Zipursky. 1991. "Induction in the Developing Compound Eye of Drosophila: Multiple Mechanisms Restrict R7 Induction to a Single Retinal Precursor Cell." Cell 67 (6): 1145-55.

Verstreken, Patrik, Tong-Wey Koh, Karen L. Schulze, R. Grace Zhai, P. Robin Hiesinger, Yi Zhou, Sunil Q. Mehta, Yu Cao, Jack Roos, and Hugo J. Bellen. 2003. "Synaptojanin Is Recruited by Endophilin to Promote Synaptic Vesicle Uncoating." Neuron 40 (4): 733-48.

Vogt, Katrin, Christopher Schnaitmann, Kristina V. Dylla, Stephan Knapek, Yoshinori Aso, Gerald M. Rubin, and Hiromu Tanimoto. 2014. "Shared Mushroom Body Circuits Underlie Visual and Olfactory Memories in Drosophila." eLife 3 (August): e02395.

Weiss, Linnea A., Anupama Dahanukar, Jae Young Kwon, Diya Banerjee, and John R. Carlson. 2011. "The Molecular and Cellular Basis of Bitter Taste in Drosophila." Neuron 69 (2): 258-72.

Wiegert, J. Simon, and Thomas G. Oertner. 2016. "How (not) to Silence Long-Range Projections with Light." Nature Neuroscience 19 (4): 527-28.

Wietek, Jonas, J. Simon Wiegert, Nona Adeishvili, Franziska Schneider, Hiroshi Watanabe, Satoshi P. Tsunoda, Arend Vogt, Marcus Elstner, Thomas G. Oertner, and Peter Hegemann. 2014. "Conversion of Channelrhodopsin into a Light-Gated Chloride Channel." Science 344 (6182): 409-12.

Wu, Ming-Chin, Li-An Chu, Po-Yen Hsiao, Yen-Yin Lin, Chen-Chieh Chi, Tsung-Ho Liu, Chien-Chung Fu, and Ann-Shyn Chiang. 2014. "Optogenetic Control of Selective Neural Activity in Multiple Freely Moving Drosophila Adults." Proceedings of the National Academy of Sciences of the United States of America 111 (14): 5367-72.

Yildizoglu, Tugce, Jan-Marek Weislogel, Farhan Mohammad, Edwin S-Y Chan, Pryseley N. Assam, and Adam Claridge-Chang. 2015. "Estimating Information Processing in a Memory System: The Utility of Meta-Analytic Methods for Genetics." PLoS Genetics 11 (12): e1005718.

Zemelman, Boris V., Georgia A. Lee, Minna Ng, and Gero Miesenbock. 2002. "Selective Photostimulation Neurotechnique of Genetically ChARGed Neurons." Neuron 33: 15-22.

Zhang, Feng, Li-Ping Wang, Martin Brauner, Jana F. Liewald, Kenneth Kay, Natalie Watzke, Phillip G. Wood, et al. 2007. "Multimodal Fast Optical Interrogation of Neural Circuitry." Nature 446 (7136): 633-39. 